\title{
Wait times for sleep apnea care in Ontario: A multidisciplinary assessment
}

\author{
Brian W Rotenberg MD MPH FRCSC ${ }^{1}$, Charles F George MD FRCPC ${ }^{2}$, \\ Kevin M Sullivan PhD MPH MHA ${ }^{3}$, Eric Wong MD MCISC(FM) CCFP4
}

\begin{abstract}
BW Rotenberg, CF George, KM Sullivan, E Wong. Wait times for sleep apnea care in Ontario: A multidisciplinary assessment. Can Respir J 2010;17(4):170-174.
\end{abstract}

BACKGROUND: Obstructive sleep apnea (OSA) is a highly prevalent disorder that is associated with significant patient morbidity and societal burden. In general, wait times for health care in Ontario are believed to be lengthy; however, many diseases lack specific corroborative wait time data.

OBJECTIVE: To characterize wait times for OSA care in Ontario. METHODS: Cross-sectional survey. A survey tool was designed and validated to question physicians involved in OSA care about the length of the wait times their patients experience while traversing a simplified model of OSA care. The survey was sent to all otolaryngologists and respirologists in the province, as well as to a random sample of provincial family physicians. RESULTS: Patients waited a mean of 11.6 months to initiate medical therapy (continuous positive airway pressure), and 16.2 months to initiate surgical therapy. Sleep laboratory availability appeared to be the major restriction in the patient management continuum, with each additional sleep laboratory in a community associated with a $20 \%$ decrease in overall wait times. Smaller community sizes were paradoxically associated with shorter wait times for sleep studies $(\mathrm{P}<0.01)$ but longer wait times for OSA surgery $(\mathrm{P}<0.05)$. Regression analysis yielded an $\mathrm{r}^{2}$ of 0.046 ; less than $5 \%$ of the wait time variance could be explained by the simplified model. CONCLUSION: Patients experienced considerable wait times when undergoing management for OSA. This has implications for both individual patient care and public health in general.

Key Words: Obstructive sleep apnea; Polysomnogram; Sleep study; Snoring; Uvulopalatopharyngoplasty; Wait times

$\mathrm{T}$ he prevalence of obstructive sleep apnea (OSA) in the adult population is estimated to be $2 \%$ in women and $4 \%$ in men $(1,2)$. With the increasing rate of obesity $(1)$, both the incidence and prevalence of OSA are also rising. OSA is recognized to be associated with a wide variety of detrimental health effects such as daytime somnolence, reduced concentration, headaches and memory loss. Many studies have demonstrated OSA to be a risk factor for fatal and nonfatal cardiovascular disease (1-3), neurological disease $(1,2,4)$ and all-cause mortality $(2,5,6)$. OSA is known to be significantly associated with fatal and nonfatal motor vehicle accidents $(1,7)$, and also has deleterious effects on economic productivity. The Public Health Agency of Canada and the Canadian Thoracic Society both have indicated that OSA is a public health threat $(2,4)$.

In 1992, the Canadian Medical Association reported (8) on disparities in health care accessibility across these domains

\author{
Les temps d'attente pour les soins de l'apnée du \\ sommeil en Ontario : Une évaluation \\ multidisciplinaire
}

\begin{abstract}
HISTORIQUE : L'apnée obstructive du sommeil (AOS) est un trouble à forte prévalence qui s'associe à une morbidité et à un fardeau sociétal considérables pour le patient. En général, on croit les temps d'attente très longs avant de recevoir des soins en Ontario. Cependant, de nombreuses maladies ne s'associent à aucunes données corroboratives précises sur les temps d'attente.

OBJECTIF : Caractériser les temps d'attente pour les soins de l'AOS en Ontario.

MÉTHODOLOGIE : Un outil afin de procéder à une étude transversale a été conçu et validé en vue d'interroger les médecins participant aux soins de l'AOS au sujet des temps d'attente que connaissent leurs patients lorsqu'ils sont exposés à un modèle simplifié de soins de l'AOS. Tous les otorhinolaryngologistes et pneumologues de la province l'ont reçu, de même qu'un échantillon aléatoire de médecins de famille de la province.

RÉSULTATS : Les patients ont attendu en moyenne 11,6 mois pour amorcer le traitement médical (pression positive continue), et 16,2 mois pour amorcer le traitement chirurgical. La disponibilité des laboratoires du sommeil semblait la principale restriction dans le continuum de prise en charge des patients, chaque nouveau laboratoire de sommeil installé dans une collectivité s'associant à une diminution de $20 \%$ des temps d'attente globaux. Paradoxalement, les plus petites collectivités s'associaient à des temps d'attente plus courts pour procéder aux études du sommeil $(\mathrm{P}<0,001)$ mais à des temps d'attente plus longs avant l'opération contre l'AOS $(\mathrm{P}<0,05)$. L'analyse de régression a donné lieu à un $\mathrm{r}^{2}$ de 0,046 . Moins de $5 \%$ de la variance de temps d'attente s'expliquait par le modèle simplifié.

CONCLUSION : Les patients ont dû affronter des temps d'attente considérables pour la prise en charge de l'AOS, ce qui a des conséquences à la fois sur les soins individuels aux patients et sur l'ensemble de la santé publique.
\end{abstract}

and others. Not only did patients have widely differing rates of physician access, but they also had differential access to resources such as medical imaging and diagnostic testing. Although OSA resources were not specifically studied in this report, there is every reason to suspect that access to resources for diagnosis and treatment of OSA would be just as variable and inconsistent. Access to health care was reported to be the top unmet health need by more than $32 \%$ of respondents to a 2003 Statistics Canada survey (9). Wait times for specialist care and for diagnostic services were both ranked as the top issue of public concern $(9,10)$.

Ontario has a highly variable health care access landscape, with an array of rural and urban community practices as well as multiple medical schools affiliated with university-based tertiary care hospitals. Although wait time reduction initiatives have been undertaken in several key areas in Ontario, a barrier

${ }^{1}$ Department of Otolaryngology - Head $\mathcal{E}$ Neck Surgery; ${ }^{2}$ Division of Respirology, Department of Medicine, University of Western Ontario, London, Ontario; ${ }^{3}$ Department of Epidemiology, Emory University, Atlanta, Georgia, USA; ${ }^{4}$ Department of Family Medicine, University of Western Ontario, London, Ontario

Correspondence: Dr Brian W Rotenberg, St Joseph's Health Centre, 268 Grosvenor Street, Room E3-104, London, Ontario N6A 4V2.

Telephone 519-646-6320, fax 519-646-6173, e-mail brian.rotenberg@sjhc.london.on.ca 
to developing these same initiatives in other areas of care is a lack of data regarding disease-specific wait times. The primary objective of the present study was to gather data describing the pattern of wait times for OSA treatment in Ontario and to describe the overall wait time a patient with OSA experiences during their health care management process. A secondary objective was to characterize parameters that may influence these wait times.

\section{METHODS}

The present research study was approved by the University of Western Ontario (London, Ontario) Research Ethics Board. Wait time data were collected via cross-sectional survey of the main physician groups involved in OSA care: family physicians (FPs), respirologists (RESPs) and otolaryngologists (ENTs). Triangulation of wait-time data from these three sources painted a picture of the overall length of time patients wait for OSA management.

\section{Survey tool development and validation}

For study purposes, a simplified model of the typical OSA care pathway was developed, reflecting the time points patients encounter during their management (Figure 1). The arrows indicate intervals during which patients wait - these time intervals were the main outcome measure of the study. A survey tool was developed to incorporate respondent demographic and wait time data. Respondents estimated the wait time that their patients experienced for each of the intervals. Wait time intervals were grouped into a six-item ordinal scale as follows: less than one month, one to three months, four to six months, seven to nine months, 10 to 12 months and longer than 12 months. The physician demographic variables recorded were the following: speciality (ie, FP, ENT or RESP), age, sex, years in practice, size of practice (measured by an estimate of the number of active patients in the practice), practice location (urban, small town, rural or remote) and practice type (academic versus nonacademic, and solo versus group practice). Respondents were also queried about the number of sleep laboratories in their catchment area.

The survey tool was validated with an 11-respondent pilot study, during which reliability estimates were also calculated. Wait time estimates for each step of the study model were compared with actual wait times assessed via formal chart review. Both construct validity and test-retest reliability were assessed by comparing means and SDs for each parameter pair and by calculating Cronbach's alpha $(\alpha)$, with $\alpha>0.70$ set as the a priori threshold for acceptability. Proximity of the means served to gauge measurement accuracy, while proximity of the SDs acted as the benchmark for measurement precision. The overall mean $\alpha$ of the survey items was 0.931 for validation assessment and 0.871 for reliability assessment - both values were well above the a priori threshold value. The survey was, therefore, deemed to be reliable and valid as a tool for the present project.

\section{Sample size calculation}

The survey was initially designed to be distributed across Canada, with sample size estimates calculated accordingly. However, a low response rate from all provinces other than Ontario hampered the planned distribution; consequently, the sample size calculation was revised accordingly to reflect an Ontario-only distribution. The provincial sample pool consisted of approximately 228 RESPs, 226 ENTs and 10,328 FPs (based

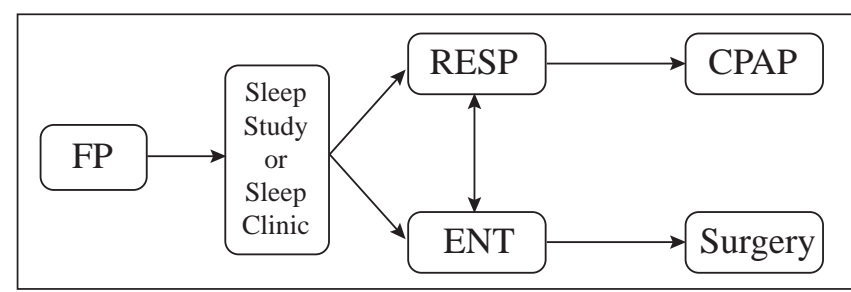

Figure 1) The simplified model of the typical obstructive sleep apnea care pathway developed for the surveys. CPAP Continuous positive airway pressure; ENT Otolaryngologist; FP Family physician; RESP Respirologist

on 2007 National Physician Survey data [11]). Sample size estimates were generated to detect a $25 \%$ difference between groups with $95 \%$ confidence and $80 \%$ power. This resulted in a final per group sample size requirement of 80 completed surveys and 160 surveys sent per physician group (based on an anticipated response rate of $50 \%$ ) to detect a $25 \%$ difference between groups. A decision was made to send surveys to all Ontario RESPs and ENTs, and to a random sample fraction (4\% [n=400]) of the FPs. Randomization of the FP group was performed using tools available at www.random.org.

\section{Survey distribution and collection}

For RESPs and ENTs, the survey was distributed as a weblink on www.surveymonkey.com, with an e-mail sent to Ontario members of the respective national societies requesting their participation. Embedded measures in the online survey were designed to preserve both anonymity and prevent an individual from completing the survey more than once. There was no e-mail registry for FPs; instead, a formal written survey was mailed with self-addressed, stamped, return envelopes. A modified Dillman survey protocol was used to improve response rates.

\section{Statistical analysis}

Data were analyzed using SPSS version 12.0 (SPSS Inc, USA). Analysis was performed excluding all continuous variable outlier values below the first and above the 99th percentile. Continuous, normally distributed variables were compared using ANOVA. Nominal and ordinal variables were compared using $\chi^{2}$ analysis. The nonparametric Kruskal-Wallis test was used for analyis involving the three groups, while the Mann-Whitney $U$ test was used to analyze between-group differences. In addition, each dependent variable was recoded to a binomial ordinal variable differentiating between three months and less, and greater than three months. Bivariate analysis to identify correlations between variable pairs was performed with Pearson correlation coefficients. Logistic regression models were developed, with all twoway interactions being tested for. A two-tailed $\mathrm{P}<0.05$ was considered to be statistically significant.

\section{Sample description}

\section{RESULTS}

Data regarding the three physician groups are presented in Table 1. A high response rate was achieved from ENTs (91.6\%) and RESPs $(72.4 \%)$, with a lower response rate from FPs (47.5\%). All demographic and practice descriptor variables were significantly different between groups, except for sex distribution. The demographic data were compared with the 2007 National Physician Survey (11) and found to be consistent, 
TABLE 1

Sample demographics

\begin{tabular}{lrrrcc}
\hline & \multicolumn{3}{c}{ Specialty } & \multirow{2}{*}{ Test } \\
\cline { 2 - 4 } & ENT & RESP & FP & statistic & P \\
\hline Total population, $\mathrm{n}$ & 225 & 225 & 10,000 & - & - \\
Sample population, n & 225 & 225 & 400 & - & - \\
Sample fraction, \% & 100 & 100 & 4 & - & - \\
Response rate, \% & 91.6 & 72.4 & 47.5 & - & - \\
Age, years (mean) & 46.1 & 46.5 & 53.9 & $46.207^{*}$ & $<0.001$ \\
Sex, \% female & 27.7 & 32.5 & 38.1 & $22.528^{\dagger}$ & 0.087 \\
Years in practice, n (mean) & 13.9 & 14.2 & 22.3 & $55.771^{*}$ & $<0.001$ \\
Practice location, \% urban & 82.7 & 82.7 & 61.6 & $22.258^{\dagger}$ & $<0.001$ \\
Practice type, \% academic & 36.9 & 42.9 & 9.5 & $56.394^{\dagger}$ & $<0.001$ \\
Practice type, \% group & 53.4 & 55.2 & 77.4 & $30.648^{\dagger}$ & $<0.001$ \\
Size of practice, n (mean) & 4997 & 3939 & 1969 & $27.230^{*}$ & $<0.001$ \\
\hline
\end{tabular}

ENT Otolaryngology; FP Family physician; RESP Respirology. *ANOVA; ${ }^{\dagger}$ Pearson's $\chi^{2}$

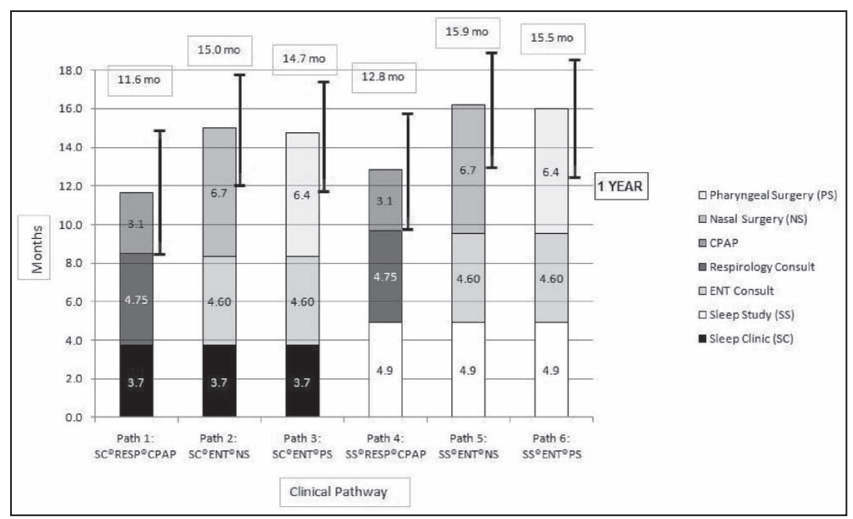

Figure 2) Overall wait times experienced by obstructive sleep apnea patients as they traversed the health care system in Ontario. CPAP Continuous positive airway pressure; ENT Otolaryngologist; mo Months; RESP Respirologist

suggesting that the respondents were an adequate and representative sample.

\section{Wait time perceptions}

Family physicians were asked how long it took for a patient to be seen in a sleep clinic, be seen by an ENT, be seen by a RESP and to undergo a sleep study. The most common response for most wait times in the first, third and fourth scenario was ' 1 to 3 months' (40.3\%), whereas for an ENT referral, the most common wait time was ' 4 to 6 months' $(40.1 \%)$. Approximately $50 \%$ of the responses indicated a wait time of longer than three months for all intervals. The average estimate of the number of sleep laboratories in an FP catchment area was 2.1. ENTs and RESPs were asked about wait times for the following:

1. Sleep clinic;

2. Sleep study;

3. ENT or RESP consultation;

4. Continuous positive airway pressure (CPAP) initiation;

5. Nasal surgery; and

6. Pharyngeal surgery.

For ENTs, the most common response was '1 to 3 months' for items 1 to 4 (36.5\%, 34.0\%, 59.5\%, 45.1\% and 51.6\%, respectively) except those relating to nasal or pharyngeal surgery, for
TABLE 2

Top three reasons for long wait times rated according to specialty

\begin{tabular}{|c|c|c|c|c|c|c|}
\hline \multirow[b]{3}{*}{ Factor } & \multicolumn{6}{|c|}{ Rating } \\
\hline & \multicolumn{3}{|c|}{ Otolaryngology } & \multicolumn{3}{|c|}{ Respirology } \\
\hline & 1st & 2nd & 3rd & $1 s t$ & 2nd & 3rd \\
\hline Inadequate clinic time & 4.9 & 10.7 & 7.3 & 6.1 & 16.0 & 6.1 \\
\hline Inadequate OR time & 8.3 & 6.8 & 5.3 & 5.5 & 2.5 & 1.8 \\
\hline Not enough sleep labs & 18.9 & 11.2 & 3.9 & 16.0 & 7.4 & 6.7 \\
\hline Inadequate awareness & 8.7 & 9.7 & 9.7 & 6.7 & 6.1 & 9.8 \\
\hline Not enough specialists & 4.4 & 8.3 & 7.3 & 8.0 & 6.1 & 6.1 \\
\hline Cost to patient & 2.4 & 3.4 & 6.8 & 1.2 & 4.9 & 3.7 \\
\hline
\end{tabular}

Data presented as \%. labs Laboratories; OR Operating room

which the most common response was ' 7 to 9 months' $(34.5 \%$ and $35.8 \%$, respectively). RESPs had a modal response of ' 1 to 3 months' for items 1,3 and 4 (40.3\%, 52.3\% and $40.7 \%$, respectively) except for sleep studies and either type of surgery, for which modes were ' 4 to 6 months', ' 7 to 9 months' and ' 7 to 9 months' $(35.5 \%, 32.7 \%$ and $43.8 \%$, respectively). Again, approximately $50 \%$ of responses indicated a longer wait time than three months for the time intervals. The average number of sleep laboratories in the ENTs catchment area was 3.1, comparable with that of RESPs (2.8). There was no statistically significant difference between physician groups at $\mathrm{P}=0.05$ for any of the other wait time intervals, with means compared using ANOVA or, nonparametrically, using $\chi^{2}$ analysis.

Although the modal responses from the three physician groups for most wait time situations were ' 1 to 3 months', there was a very large proportion of answers in excess of this also. To examine this issue, responses were converted to a binomial value of three months or less versus greater than three months. In this analysis, there was a large proportion of patients waiting longer than three months per scenario (average 54.5\%); this rose to almost $80 \%$ of patients waiting longer than three months for any surgical intervention. FPs reported a slightly shorter overall wait time for sleep studies compared with RESPs and ENTs $\left(\chi^{2}=7.210\right.$, degrees of freedom $=2 ; \mathrm{P}=0.027$ ), but this was not clinically significant. No other statistical difference across groups was noted at $\mathrm{P}=0.05$, indicating good agreement among the groups.

Figure 2 shows the overall wait times experienced by patients as they traversed the health care system, determined by calculating the mean of the modal ordinal wait time data per interval. The shortest wait time appeared to be for patients who were initially referred to a sleep clinic (mean wait time 3.7 months), subsequently referred to a RESP (mean wait time 4.75 months) and finally initiated on CPAP treatment (mean wait time 3.1 months), for a total mean wait time of 11.6 months to therapy initiation. The longest wait time appeared to be for patients initially referred for a sleep study (mean wait time 4.9 months), subsequently referred to an ENT (mean wait time 4.6 months) and to finally undergo nasal surgery (6.7 month wait), for a total mean wait time of 16.2 months to therapy initiation. The other pathway permutations fall between these two.

Reasons for long wait times are indicated in Table 2. Too few sleep laboratories, inadequate clinic time, inadequate operating room (OR) time and inadequate patient awareness were all rated in the top three by between $20 \%$ and $30 \%$ of ENT and RESP respondents. Pearson $\chi^{2}$ analysis revealed no statistically significant difference between the responses of the two specialties. 


\section{Predictors of wait times}

Pearson correlation coefficients were calculated for wait time intervals versus demographic and practice descriptor variables. Correlations were weak $(\mathrm{r}<0.4)$ and none were significant. No significant two-way interactions were identified in the regression analyses. Two variables were predictors of wait times for a sleep clinic visit: community size $(\mathrm{P}<0.01)$, with smaller community size associated with shorter wait times; and number of sleep laboratories $(\mathrm{P}<0.001)$, with increasing number of sleep laboratories associated with shorter wait times. Time to pharyngeal surgery had one predictive variable - community size $(\mathrm{P}<0.05)$. No other significant predictors were identified.

\section{DISCUSSION}

Long wait times for OSA care in Ontario have been anecdotally suspected; however, the present study was the first to scientifically demonstrate the surprisingly lengthy care delays experienced by these patients. In the simplified model of care studied in the present survey, patients waited a mean of 11.6 months for CPAP initiation, and 16.2 months for surgical therapy. These wait times represent imprecise data because they are idealized, do not take into account the various possible care permutations or the high rate of first-line therapy failure necessitating a second attempt (as high as $50 \%$ in some studies $[1,4,6]$ ). In other words, even the lengthy wait times documented in the current study underestimate those experienced by most patients with OSA the actual wait times for care are likely longer. Such long delays for health care for this highly prevalent disease are a potential threat to public health in the province.

Before the current study, no Canadian data describing wait times for OSA care across the treatment continuum were available. From the Ontario perspective, the only aspect of OSA care that had been studied to date was that of access to sleep laboratories for sleep studies (12). Use of this test in Ontario increased by almost 200\% in the 10 years between 1996 and 2005, and 25\% from 2004 to 2005 (13). Consistent with this, our study demonstrated that sleep laboratory availability significantly contributed to the delay for OSA care; conversely, each increase in the number of sleep laboratories was associated with a 20\% decrease in wait time for OSA care. These data carry external validity to other provinces in that Canada's health care system is relatively homogeneous, such that the issues faced by Ontario patients will be closely analogous to those faced by patients in other provinces. This suggests that diagnostic strategies that use clinical prediction and ambulatory sleep monitoring should be developed for patients with suspected OSA, and should not solely depend on sleep studies.

Two other factors were identified as weakly predictive of OSA management wait times: community size and the need for surgery. Community size was negatively correlated in that small communities seemed to have a shorter wait times for diagnostic testing. This is somewhat perplexing because smaller communities do not typically have their own sleep laboratory and must, therefore, refer patients to larger centres. This finding may reflect a hypothetically higher rate of ambulatory sleep assessments in smaller communities or, alternatively, may simply be spurious. The lengthy surgical wait times speak to the well-known lack of OR time for these patients, the majority of whom are CPAP failures $(1,4)$. This is of concern given that the Canadian Thoracic Society guidelines suggest that pharyngeal surgery may be considered in selected patients with OSA who have failed CPAP and/or oral appliance therapy (4). Without a timely surgical option, these patients are left without recourse. It is interesting to speculate on why the identified correlations for these items were so weak and why the $r^{2}$ in the regression analysis was so low. The issue of wait times is multifactorial within the Canadian health care system; consequently, it is not entirely surprising that no single physician factor was shown to demonstrably affect it. Therefore, wait time issues may relate more to system-wide resources or to patient-specific factors.

Prospective observational cohort studies suggest that CPAP may decrease cardiovascular morbidity and reduce motor vehicle accident rates $(14,15)$. Conversely, several studies have shown that OSA - as a comorbid condition - raises health care costs in general. Kapur et al (16) reported on the medical costs of 238 consecutive patients in the United States who had OSA as a comorbid diagnosis; the mean annual medical cost was $\$ 2,720$ greater per patient before diagnosis compared with age-, body mass index - and sex-matched controls. Bahammam et al (17) identified that by the time patients were finally diagnosed with OSA, they had already been heavy users of health services for several years, and in excess of the use of the general population. Moreover, once a diagnosis of OSA was made and treatment initiated, evidence suggested that health care expenses markedly decreased by almost 50\%. Although Canada-specific data regarding this topic are sparse, one study by Peker et al (18) reported hospital stays of 1.27 days per patient per year before OSA diagnosis, which decreased to 0.53 days per patient per year after diagnosis. Importantly, these improvements were only seen in patients who had initiated and adhered to CPAP treatment. When treatment delays are prolonged, as our study demonstrated, patients suffer and health care costs rise.

The present study has several potential limitations. As with all surveys, questions can be misinterpreted. Ideally, our initial survey validation should have mitigated the severity of this problem. Also, respondents estimated ordinal wait times for their patients, as opposed to conducting a formal medical record review to ascertain precise wait times. However, asking respondents to formally review their own records would have substantially compromised the response rate. Selection bias exists in the form of the relatively low response rate of the FP arm, thus resulting in a potentially nonrepresentative sample. Our random sample, however, matched the demographics identified in the 2007 National Physician Survey, suggesting that adequate representation was achieved. Also, it may have been helpful to know the estimated number of patients per year that the physician referred for sleep studies because it may have affected the wait time outcomes and statistical results. An additional potential source of bias was that of physicians possibly overestimating their wait times in the knowledge that publication of data regarding longer wait times creates pressure for government to provide more resources.

The most important consideration in interpreting our results was that the survey was based on a simplified model of OSA care. We idealized the care process by assuming that patients underwent linear progression between discrete points along the management spectrum without backtracking, and without failure of initial therapy at the end. This is not a fully accurate reflection of reality, wherein there are many other care permutations that could potentially have been measured. Thus, our simplified model was able to paint a basic picture of the wait time 
issue for OSA. However, the reality is likely an analogous - but different and probably more severe - wait time problem for the management of OSA in the province of Ontario.

ACKNOWLEDGEMENTS: The authors acknowledge Mr Irvin Sherman for his assistance in preparing this manuscript.

\section{REFERENCES}

1. Young T, Palta M, Dempsey J, Skatrud J, Weber S, Badr S. The occurrence of sleep disordered breathing among middle aged adults. N Engl J Med 1993;328:1230-5.

2. Life and breath: Respiratory disease in Canada (OSA). $<$ http://www.phac-aspc.gc.ca/publicat/2007/lbrdc-vsmrc/sleepsommeil-eng.php> (Accessed on May 7, 2009).

3. Nieto F, Young TB, Lind BK, et al. Association of sleep-disordered breathing, OSA, and hypertension in a large community-based study. JAMA 2000;283:1829-36.

4. Fleetham JA, Ayas N, Bradley D, et al; CTS Sleep Disordered Breathing Committee. Canadian Thoracic Society Guidelines: Diagnosis and treatment of sleep disordered breathing in adults. Can Respir J 2006;13:1-7.

5. Marshall NS, Wong KK, Liu PY, Cullen SR, Knuiman MW, Grunstein RR. OSA as an independent risk factor for all-cause mortality: The Busselton Health Study. Sleep 2008;31:1079-85.

6. Pack A, Platt A, Pien G. Does untreated obstructive OSA lead to death? Sleep 2008;31:1067-8.

7. Young T, Blustein J, Finn L, Palta M. Sleep-disordered breathing and motor vehicle accidents in a population-based sample of employed adults. Sleep 1997;20:608-13.

8. Canadian Medical Association, Report of the Advisory Panel on the Provision of Medical Services in Underserviced Regions, 1992.
National Anti-Poverty Organization. Rural Health. $<$ http://dsp-psd. pwgsc.gc.ca/Collection-R/LoPBdP/BP/bp325-e.htm> (Accessed on June 9, 2010).

9. Statistics Canada. Access to Health Care Services in Canada, 2003. $<$ http://www.statcan.ca/english/freepub/82-575-XIE/2003001/report. htm> (Accessed on May 9, 2006).

10. Sanmartin C, Berthelot JM, McIntosh CM. Determinants for unacceptable waiting times for specialized services in Canada. Healthc Policy 2007;2:140-54.

11. National Physician Survey, 2007. <http://www. nationalphysiciansurvey.ca/nps/2007_Survey/2007results-e.asp> (Accessed on Oct 9, 2009).

12. Flemons WW, Douglas NJ, Kuna ST, Rodenstein DO, Wheatley J. Access to diagnosis and treatment of patients with suspected OSA. Am J Respir Crit Care Med 2004;169:668-72.

13. You JJ, Alter DA, Iron K, et al. Diagnostic Services in Ontario: Descriptive analysis and jurisdictional review. ICES Investigative Report. Toronto: Institute for Clinical Evaluative Sciences, 2007.

14. George CF. Reduction in motor vehicle collisions following treatment of sleep apnoea with nasal CPAP. Thorax 2001;56:508-12.

15. Marin J, Carrizo S, Vicente E, Agusti A. Long-term cardiovascular outcomes in men with obstructive sleep apnoea-hypopnoea with or without treatment with continuous positive airway pressure: An observational study. Lancet 2005;365:1046-53.

16. Kapur V, Blough DK, Sandblom RE, et al. The medical cost of undiagnosed OSA. Sleep 1999;22(Suppl 6):749.

17. Bahammam A, Delaive K, Ronald J, Manfreda J, Roos L, Kryger MH. Health care utilization in males with obstructive OSA syndrome two years after diagnosis and treatment. Sleep 1999;22(Suppl 6):740-7.

18. Peker Y, Hedner J, Johansson A, Bende M. Reduced hospitalization with cardiovascular and pulmonary disease in obstructive OSA patients on nasal CPAP treatment. Sleep 1997;20:645-53. 


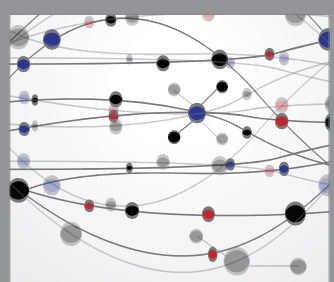

The Scientific World Journal
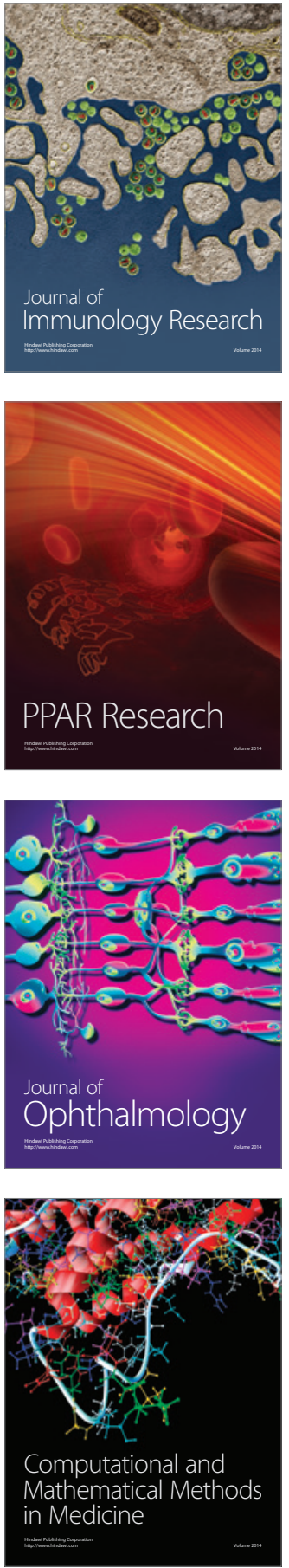

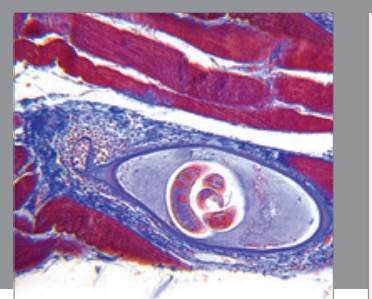

Gastroenterology Research and Practice

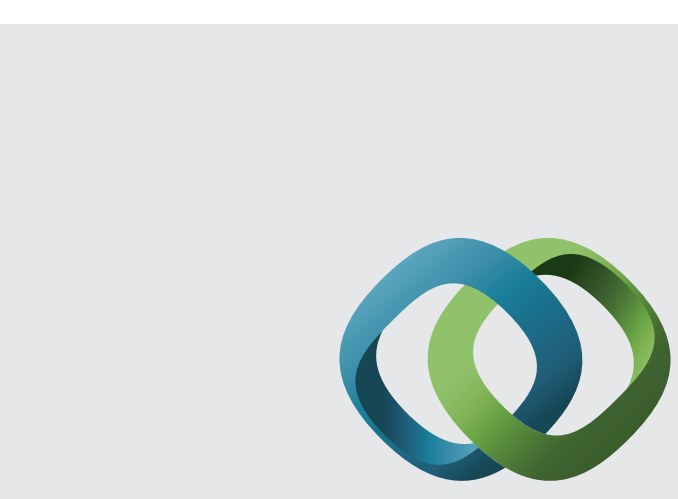

\section{Hindawi}

Submit your manuscripts at

http://www.hindawi.com
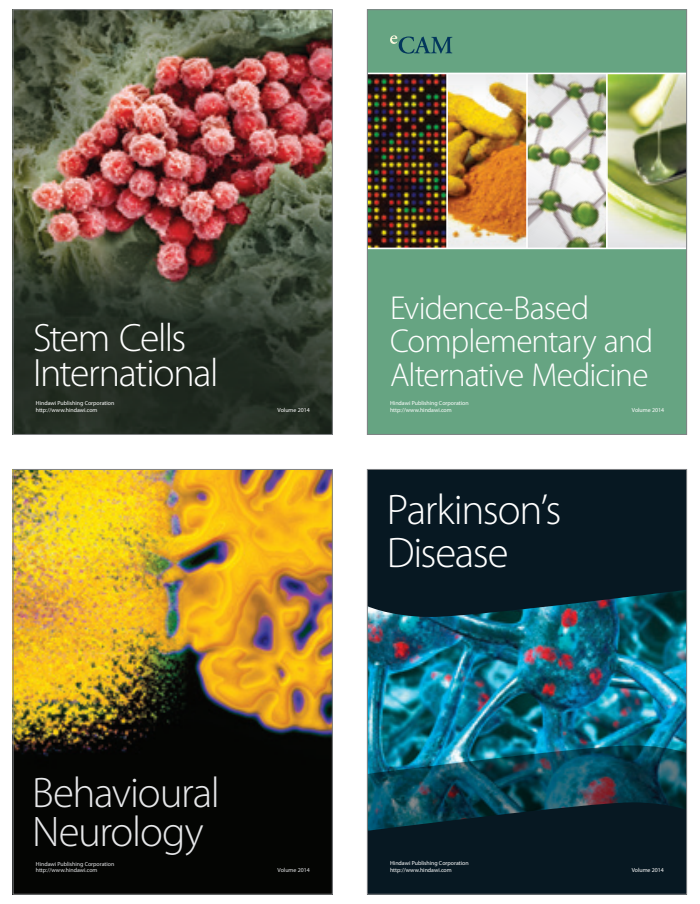
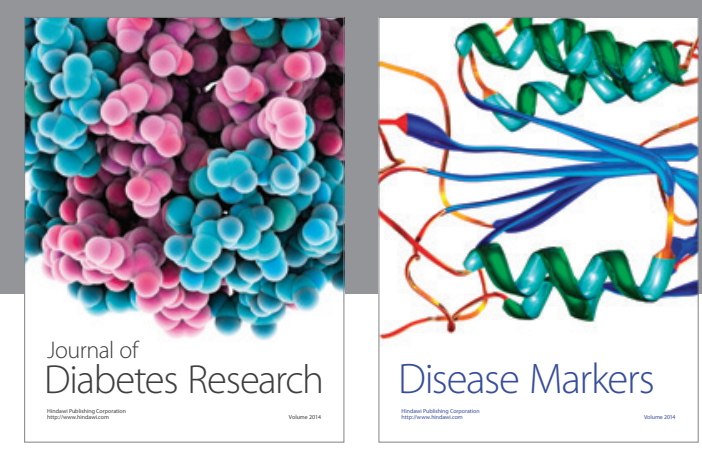

Disease Markers
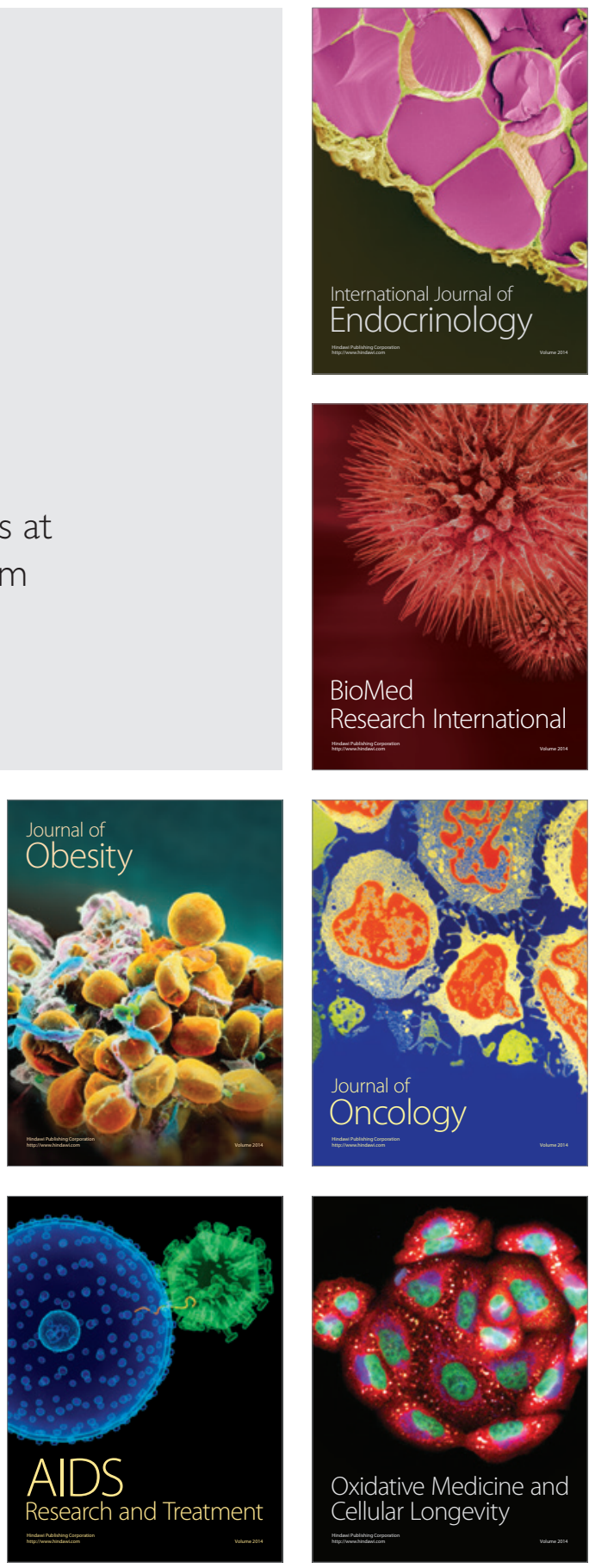